\title{
Effects of oxygen on the growth of Desulfovibrio desulfuricans
}

\author{
Hamid AbDollahi and Julian W. T. WimpenNY* \\ School of Pure and Applied Biology, University of Wales, College of Cardiff, PO Box 915, Cardiff CF1 3TL, UK
}

(Received 6 September 1989; revised 21 December 1989; accepted 11 January 1990)

\begin{abstract}
Desulfovibrio desulfuricans survived exposure to air on the surface of agar plates for at least $48 \mathrm{~h}$. Under continuous culture conditions two effects of low oxygen partial pressures $(10-15 \mathrm{mmHg})$ were noted: (1) a relief of inhibition by $\mathrm{H}_{2} \mathrm{~S}$; (2) specific inductive responses to oxygen including an increase in cell respiration (two- to threefold) and in levels of cytochrome $c$ (about $20 \%$ ), and a rise in the activities of NADH oxidase (threefold) and superoxide dismutase (tenfold). At oxygen partial pressures greater than about $15 \mathrm{mmHg}$, these effects were reversed, growth became progressively inhibited and the cells began to wash out of the system.
\end{abstract}

\section{Introduction}

Sulphate-reducing bacteria are important both ecologically, being responsible for the recycling of a large fraction of the organic matter that enters aquatic ecosystems (Jorgensen, 1982), and economically, in causing corrosion damage to steel and concrete structures in both aquatic and terrestrial environments (Postgate, 1984; Hamilton, 1985).

Whilst sulphate-reducing bacteria are classified as obligate anaerobes, there is growing evidence that they can survive exposure to oxygen and indeed that they might possess some of the protective mechanisms seen in a number of other anaerobic species. Hardy \& Hamilton (1981) reported that viable sulphate-reducing bacteria could be recovered from North Sea seawater. However, they could find no evidence of the NADH oxidase activity which has been implicated as an inducible oxygen-protective activity in some other anaerobes (O'Brien \& Morris, 1971; Morris, 1975; Ashley \& Shoesmith, 1977; Hoshino et al., 1978; Wimpenny \& Samah, 1978; Samah \& Wimpenny, 1982).

McCord et al. (1971) suggested that a lack of the enzyme superoxide dismutase might be one explanation for the phenomenon of obligate anaerobiosis. However, several workers later reported the presence of this activity in anaerobic bacteria (see for example Hewitt \& Morris, 1975; Wimpenny \& Samah, 1978; Samah \& Wimpenny, 1982). This enzyme was also reported to be present in Desulfovibrio desulfuricans (Hatchikian \& Henry, 1977) and in D. vulgaris (Hardy \& Hamilton, 1981).

\footnotetext{
Abbreviation: OFN, oxygen-free nitrogen
}

As part of a study into the growth of $D$. desulfuricans NCIB 8301 in pure and mixed chemostat and gradostat cultures, responses of this organism to changes in the partial pressure of oxygen were investigated and are reported in this paper.

\section{Methods}

Organism and media. Desulfovibrio desulfuricans NCIB 8301 was maintained and subcultured on medium A described by Abdollahi (1979). Medium A contained, in g per litre of distilled water: $\mathrm{K}_{2} \mathrm{HPO}_{4}$, $2 \cdot 0 ; \mathrm{NH}_{4} \mathrm{Cl}, 1 \cdot 0 ; \mathrm{Na}_{2} \mathrm{SO}_{4}, 1 \cdot 0 ; \mathrm{CaCl}_{2} .6 \mathrm{H}_{2} \mathrm{O}, 0.1$; sodium lactate, 3.5 ; yeast extract (Oxoid), 1.0; ascorbic acid, $1 \cdot 0 ; \mathrm{FeSO}_{4} \cdot 4 \mathrm{H}_{2} \mathrm{O}, 0 \cdot 1$. This solution was autoclaved at $121{ }^{\circ} \mathrm{C}$ for $15 \mathrm{~min}$ and the following added after the medium had cooled: $10 \mathrm{ml} \mathrm{10 \% (w/v)} \mathrm{filter-sterilized} \mathrm{sodium}$ thioglycollate solution; $10 \mathrm{ml} 20 \%(\mathrm{w} / \mathrm{v})$ heat-sterilized $\mathrm{MgSO}_{4} \cdot 7 \mathrm{H}_{2} \mathrm{O}$ solution. The $\mathrm{pH}$ of this medium was adjusted to $7 \cdot 0-7 \cdot 1$. Cultures were incubated at $30^{\circ} \mathrm{C}$ for $3 \mathrm{~d}$ before use.

The growth medium used in all batch and continuous culture experiments was a slightly modified version of that described as medium $\mathrm{C}$ by Postgate (1984), and contained ( $\mathrm{g}$ per litre of distilled water): $\mathrm{K}_{2} \mathrm{HPO}_{4} .3 \mathrm{H}_{2} \mathrm{O}, 1 \cdot 0 ; \mathrm{KH}_{2} \mathrm{PO}_{4}, 0.5 ; \mathrm{NH}_{4} \mathrm{Cl}, 1 \cdot 0 ; \mathrm{Na}_{2} \mathrm{SO}_{4}, 4 \cdot 5$; $\mathrm{CaCl}_{2} .6 \mathrm{H}_{2} \mathrm{O}, 0.06 ; \mathrm{MgSO}_{4} \cdot 7 \mathrm{H}_{2} \mathrm{O}, 0.06 ; \mathrm{FeSO}_{4} \cdot 7 \mathrm{H}_{2} \mathrm{O}, 0.004$; sodium citrate, 0.3 ; sodium lactate, 6.0 ; yeast extract (Oxoid), 1.0; ascorbic acid, 0.75 . The medium was adjusted to $\mathrm{pH} 7.0$ and autoclaved at $121^{\circ} \mathrm{C}$ for up to $35 \mathrm{~min}$ depending on the volume of the medium reservoir.

Survival experiments. To determine the survival of $D$. desulfuricans NCIB 8301 in air, plates containing $20 \mathrm{ml}$ medium A plus $1.5 \%(\mathrm{w} / \mathrm{v})$ agar were surface inoculated with $0.036 \mathrm{ml}$ of $10^{-2}$ - and $10^{-4}$-fold dilutions of a 3-d-old culture of the organism using a spiral plater (Spiral Systems Inc., Cincinnati, Ohio, USA). These plates were incubated aerobically for different times at $30^{\circ} \mathrm{C}$ before duplicates were removed. These were then overlaid with $20 \mathrm{ml}$ medium A plus $0.5 \%$ agar and incubated for $4 \mathrm{~d}$ at $30^{\circ} \mathrm{C}$ in anaerobic jars containing $\mathrm{H}_{2} / \mathrm{CO}_{2}$ (95:5, $\mathrm{v} / \mathrm{v})$. The number of black colonies was then determined in the appropriate sector of the spiral plate. 
Continuous culture. The organism was grown in an LHE CC 1500 magnetically stirred fermenter (LH Fermentation). The 3 litre vessel was equipped with sensors for measuring temperature, $\mathrm{pH}$, redox potential and oxygen partial pressure. Temperature was regulated at $30^{\circ} \mathrm{C}$ and $\mathrm{pH}$ in the range 6.9-7.0.

Oxygen additions were made to the gas phase by mixing oxygen with oxygen-free nitrogen (OFN) through calibrated rotameters and flostats (Platon Flow Controls, UK). Traces of oxygen were removed from the nitrogen by passing the gas over heated copper turnings in a fused silica tube heated to $350^{\circ} \mathrm{C}$ in a furnace. When very small amounts of oxygen were needed, air was pumped into the gas stream through a calibrated tubing pump (Watson-Marlowe type MHRE). Gassing regimes for the continuous culture experiments are described in Results.

The volume of medium in the fermenter was 2.5 litres. Agitation was at 150 r.p.m. and the dilution rate was $0.1 \mathrm{~h}^{-1}$. The fermenter was inoculated with $20 \mathrm{ml}$ of a $3 \mathrm{~d}$ inoculum of the organism after the medium had been gassed for a period with OFN.

Determination of growth. Growth was measured as $\mathrm{OD}_{550}$. Total counts were determined using a Thoma counting chamber.

Collection of cells. Two to four litres of cells were collected from the overflow of the vessel into a chilled receiver. Cells were harvested by centrifugation and washed in $20 \mathrm{mM}$-potassium phosphate buffer $(\mathrm{pH}$ 7.4). About $50 \mathrm{ml}$ of supernatant was retained for assay of sulphate, nitrate and fatty acids. Some of the freshly harvested cells were used immediately for $Q_{0}$, determinations; the remainder were stored at $-18^{\circ} \mathrm{C}$ until needed.

Cell breakage and fractionation. The cell paste was disintegrated using a Hughes press (Hughes, 1951) at $-25^{\circ} \mathrm{C}$ and the resultant material fractionated into particulate and soluble fractions by the procedure of Sapshead \& Wimpenny (1972).

Respiration rates. Oxygen uptake was measured polarographically as described by Lloyd \& Brookman (1967).

Enzyme assays. NADH oxidase was determined spectrophotometrically at $340 \mathrm{~nm}$ (O'Brien \& Morris, 1971). Superoxide dismutase was assayed in the soluble fraction by following the reduction of cytochrome $c$ in the presence of the xanthine oxidase superoxidegenerating system as described by McCord \& Fridovich (1969).

Cytochrome content. Cytochromes were measured in dithionitereduced versus ferricyanide-oxidized difference spectra, using a Perkin-Elmer 557 dual-wavelength spectrophotometer (Hitachi). The molar absorption coefficient of $27.5 \mathrm{~mm}^{-1} \mathrm{~cm}^{-1}$ reported for cytochrome $c 3$ by Tsuji \& Yagi (1980) was used in all calculations.

Chemical assays. Fatty acids were measured by gas-liquid chromatography using a Pye 104 system with a $2 \mathrm{~m}$ column packed with $5 \%$ FFAP on Chromosorb G 80-100 mesh (AW-DCMS; Jones Chromatography, Llanbradach, S. Glamorgan, UK). Acetate was extracted from $4 \mathrm{ml}$ culture supernatant by salting out with $1 \mathrm{~g} \mathrm{NaCl}$ and extracting the acetate into diethyl ether. Lactate was extracted by treating $1 \mathrm{ml}$ supernatant with $1 \mathrm{ml} \mathrm{14 \% (w/v)} \mathrm{boron} \mathrm{trifluoride} \mathrm{in} \mathrm{methanol.} \mathrm{The}$ mixture was allowed to stand at room temperature overnight before extracting into chloroform.

Sulphate was assayed by the barium sulphate turbidimetric method (American Public Health Association, 1971).

Nitrate was determined colorimetrically using brucine sulphate (Department of the Environment, 1969).

Hydrogen sulphide was estimated gravimerrically by passing all exhaust gases through a series of three drechsel bottles containing cadmium chloride to trap all hydrogen sulphide over a known time interval. The yellow precipitate of cadmium sulphide was collected on filter papers, dried and weighed. Sulphide production was expressed as mmol (l culture) $)^{-1} \mathrm{~h}^{-1}$

Protein was determined by the Lowry method.

\section{Results}

\section{Survival in the presence of oxygen}

D. desulfuricans NCIB 8301 was exposed to air and survival monitored as described in Methods. Loss in viability showed accelerating kinetics over the period studied (Fig. 1); however, the population survived well, especially over the first $24 \mathrm{~h}$.

\section{Establishment of continuous cultures of $D$. desulfuricans}

Cultures were grown anaerobically in the fermenter under batch conditions to ascertain the maximum

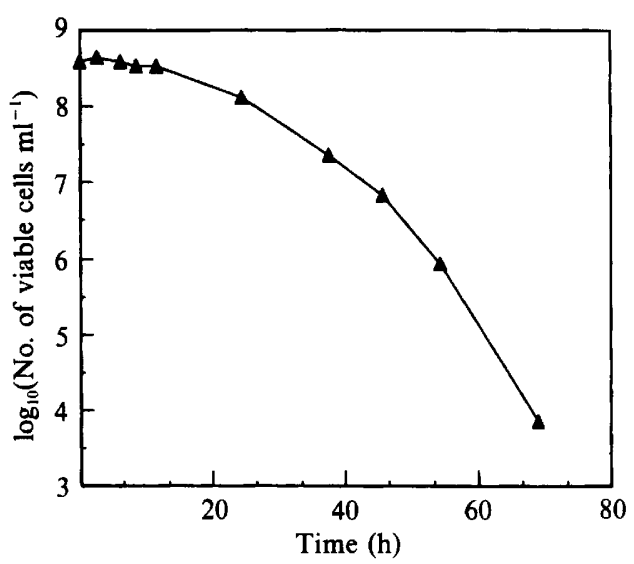

Fig. 1. Effect of exposure to air on the surface of agar plates on the survival of $D$. desulfuricans NCIB 8301.

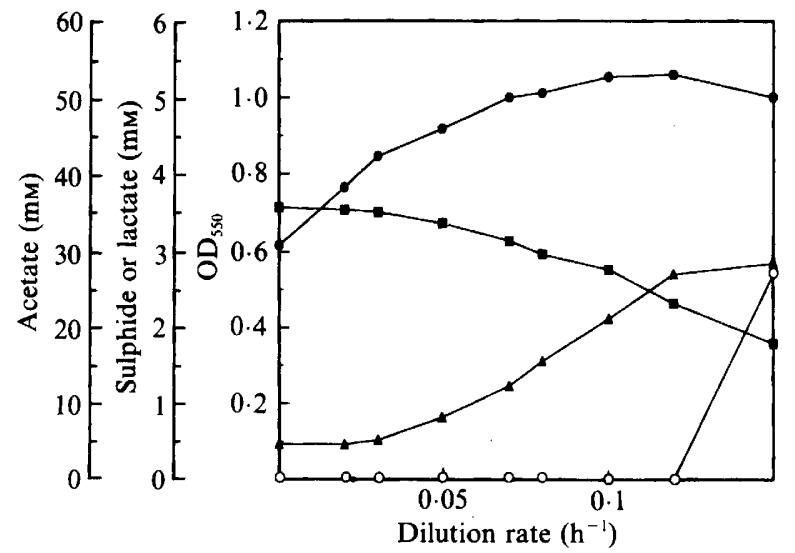

Fig. 2. Effect of dilution rate on $D$. desulfuricans NCIB 8301 cultures grown in the chemostat. $\mathbf{\square}, \mathrm{OD}_{550} ; \boldsymbol{\Delta}$, sulphide concentration; $\boldsymbol{O}$, acetate concentration; $O$, lactate concentration. The culture was gassed with $40 \mathrm{ml}$ OFN $\mathrm{min}^{-1}$. 
growth rate. During exponential growth the doubling time was about $5 \mathrm{~h}$, corresponding to a $\mu_{\max }$ value of $0 \cdot 14 \mathrm{~h}^{-1}$. The strain was then grown under continuousflow conditions in the chemostat gassed with $40 \mathrm{ml}$ OFN $\min ^{-1}$, and the dilution rate varied. Above a dilution rate of about $0.03 \mathrm{~h}^{-1}$, steady-state cell yield progressively declined. At the same time, acetate levels and the rate of sulphide production increased. Only as washout conditions were approached could lactate be detected in the vessel (Fig. 2). When stoichiometries were calculated, the ratio of acetate produced to lactate used rose from 0.58 to almost exactly 1 before dropping slightly as washout conditions were reached. The ratio of acetate used to sulphide produced was variable but was generally around $2 \cdot 5$.

\section{Effect of gassing the continuous culture with OFN}

It was predicted that gassing with OFN could influence growth by removing the main product of sulphatereduction, hydrogen sulphide. The chemostat was operated over a range of gassing rates from 0 to $1200 \mathrm{ml}$ OFN $\min ^{-1}$ and the effect on cell numbers at steady state and on redox potential was determined (Fig. 3). Increasing gassing rate increased the culture density, which reached a maximum at around $500 \mathrm{ml} \mathrm{OFN} \mathrm{min}{ }^{-1}$. The redox potential rose rapidly at first, as the flow rate of OFN was increased. In all later experiments the chemostat was operated with $500 \mathrm{ml}$ OFN $\mathrm{min}^{-1}$, since this rate appeared optimal for growth.

Effects of gas-phase $\mathrm{pO}_{2}$ on growth, redox potential and hydrogen sulphide production

The chemostat was run with seven different oxygen concentrations in the gas phase. After each change in $\mathrm{pO}_{2}$ the culture was allowed to return to steady state. Cell

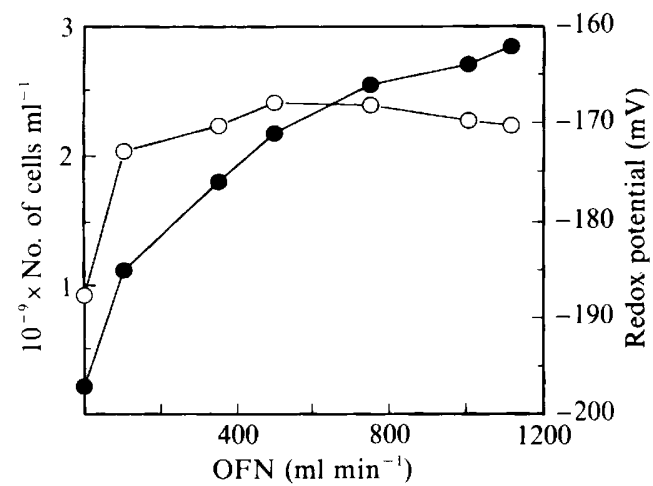

Fig. 3. Effect of gassing with OFN on population density $(O)$ and culture redox potential $(O)$ in steady-state cultures of $D$. desulfuricans NCIB 8301.

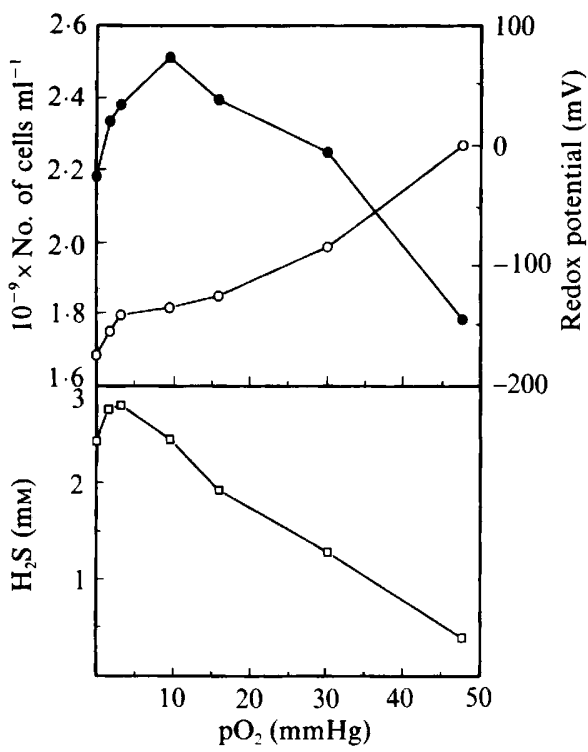

Fig. 4. Effect of gas-phase $\mathrm{pO}_{2}$ on cell density $(\odot), \mathrm{H}_{2} \mathrm{~S}$ production $(\square)$ and redox potential $(O)$ in steady-state cultures of $D$. desulfuricans NCIB 8301 .
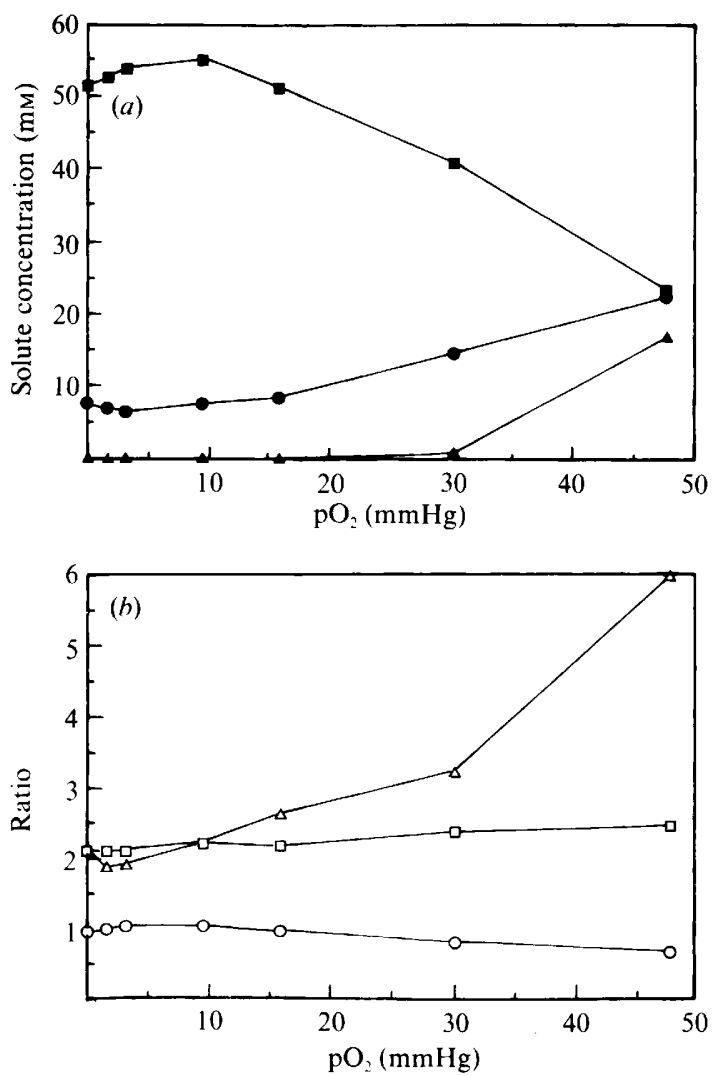

Fig. 5. (a) Effect of gas-phase $\mathrm{pO}_{2}$ on acetate $(\boldsymbol{D})$, lactate $(\boldsymbol{\Delta})$ and sulphate (O) concentrations in steady-state cultures of $D$. desulfuricans NCIB 8301. (b) Ratios of (i) acetate produced to lactate used (O); (ii) acetate produced to sulphate used ( $\square$ ); (iii) acetate produced to sulphide produced $(\triangle)$ (sulphide production data from Fig. 4). 
density increased with increasing $\mathrm{pO}_{2}$ up to about $10 \mathrm{mmHg}$, and then declined (Fig. 4). Hydrogen sulphide declined sharply above about $5 \mathrm{mmHg} \mathrm{O}$. The redox potential of the culture increased with increasing $\mathrm{pO}_{2}$.

Effects of gas-phase $\mathrm{pO}_{2}$ on sulphate, lactate and acetate concentrations in the culture

The concentration of acetate in the culture peaked at a $\mathrm{pO}_{2}$ value of about $10 \mathrm{mmHg}$ (Fig. $5 a$ ), mirroring the changes seen in cell numbers (Fig. 4). With further increases in $\mathrm{pO}_{2}$, acetate fell to less than half its highest figure before washout conditions were reached. Sulphate behaved in exactly the opposite fashion, dipping first before rising to about $20 \mathrm{mM}$ at the highest $\mathrm{pO}_{2}$ tested. Significant amounts of lactate appeared in the culture only at the highest $\mathrm{pO}_{2}$ values (Fig. $5 a$ ). The ratio of acetate produced to lactate used was close to 1 but fell to about 0.65 at the highest $\mathrm{pO}_{2}$ tested (Fig. $5 b$ ). The ratio of acetate produced to sulphate used lay between $2 \cdot 1$ and $2 \cdot 2$, increasing to about 2.5 at high $\mathrm{pO}_{2}$ values. Acetate to sulphide ratios rose from close to 2 at low $\mathrm{pO}_{2}$ values to 6 at the highest values tested (Fig. $5 b$ ).

Effect of gas-phase $\mathrm{pO}_{2}$ on the level of cytochrome $c$ and on the activities of NADH oxidase and superoxide dismutase

Cytochrome $c$ content reached a peak at a $\mathrm{pO}_{2}$ of about $15 \mathrm{mmHg}$. The activities of both NADH oxidase and superoxide dismutase were low in anaerobically grown cells and increased dramatically in the presence of very small amounts of oxygen (Fig. 6). This was particularly marked in the case of superoxide dismutase, which showed a tenfold rise in activity as the $\mathrm{pO}_{2}$ increased from zero to $10 \mathrm{mmHg}$. Above $\mathrm{pO}_{2}$ values of $10 \mathrm{mmHg}$ both enzyme activities fell.

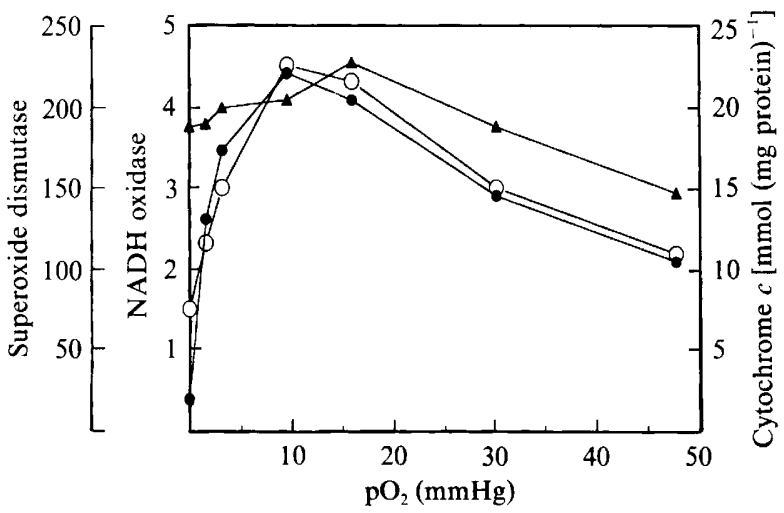

Fig. 6. Effect of gas-phase $\mathrm{pO}_{2}$ on cytochrome $c$ content $(\mathbf{A})$, and activities [mmol $\mathrm{min}^{-1}(\mathrm{mg} \text { protein) })^{-1}$ ] of NADH oxidase $(O)$ and superoxide dismutase $(O)$ in steady-state cultures of $D$. desulfuricans NCIB 8301.

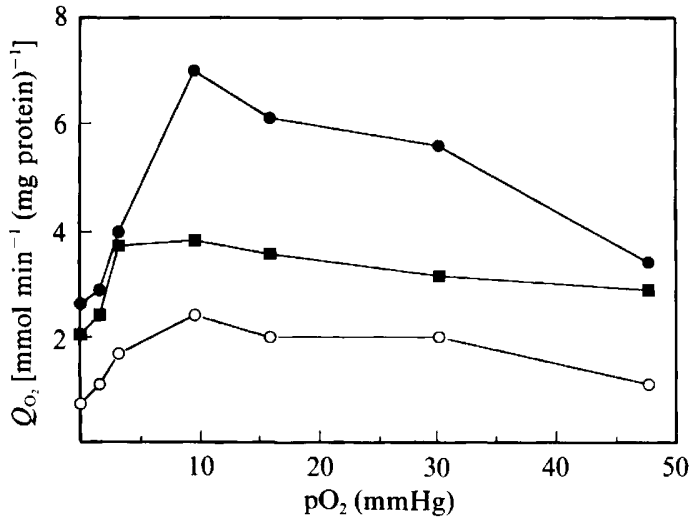

Fig. 7. Effect of gas-phase $\mathrm{pO}_{2}$ on potential respiration rates in steadystate cultures of $D$. desulfuricans NCIB 8301. O, Endogenous; $\square$, plus pyruvate; $\mathbf{O}$, plus lactate.

\section{Effect of oxygen on cellular respiration rates}

Lactate, glucose, pyruvate, acetate and ethanol were tested as possible oxidation substrates for $D$. desulfuricans NCIB 8301. Only lactate and pyruvate were oxidized at rates significantly greater than the endogenous level. Oxygen stimulated both endogenous respiration and the oxidation of pyruvate and lactate (Fig. 7). Once more there was an optimum at a $\mathrm{pO}_{2}$ of about $10 \mathrm{mmHg}$.

\section{Discussion}

The results presented above indicate that two separate phenomena govern the behaviour of Desulfovibrio desulfuricans NCIB 8301 when it is exposed to oxygen. The first concerns the inhibitory effects of the main product of sulphate reduction, hydrogen sulphide. Gassing the culture with mixtures containing oxygen would both cause chemical oxidation of hydrogen sulphide to sulphate, and remove hydrogen sulphide physically into the exhaust gases (gassing with OFN at $500 \mathrm{ml} \mathrm{min}^{-1}$ more than doubled the cell yield). In this context it is interesting that Cypionka et al. (1985) reported that not only could a number of sulphatereducing bacteria survive exposure to oxygen but they could actually grow at its expense in sulphide-oxygen counter-gradients in the absence of sulphur or sulphate. It was suggested that a limited sulphur cycle driven by the chemical oxidation of sulphide to sulphate operated here.

Another possibility is that oxygen can itself, by acting as a physiological electron acceptor, lead to additional cell yield. There is no evidence that this is the case in the present work or, as far as the authors are aware, for other 
obligate anaerobes. In contrast, the addition of oxygen to cultures of some microaerophilic organisms can increase growth yields. This was reported, for example, in continuous cultures of 'Propionibacterium shermanii' ( $P$. freudenreichii) (Pritchard et al., 1977), where small amounts of oxygen trebled cell yield.

Oxygen toxicity was manifested in several ways in the present study. After an initial increase with increasing $\mathrm{pO}_{2}$, cell yield fell to about $70 \%$ of its maximum value before washout occurred. At the same time lactate use declined, as evidenced both by a fall in acetate concentration in the medium and by the appearance of detectable lactate in the medium at the highest $\mathrm{pO}_{2}$ values (Fig. 5a). There was also a rise in sulphate concentration, indicating that oxygen toxicity was preventing its reduction to $\mathrm{H}_{2} \mathrm{~S}$ (Figs 4 and 5). Stoichiometries (Fig. $5 b$ ) indicated that one molecule of acetate was formed from each molecule of lactate at subinhibitory $\mathrm{pO}_{2}$ values but that at higher values acetate production fell to about two-thirds of this value. The ratio of acetate produced to sulphide accumulated rose markedly at the highest $\mathrm{pO}_{2}$ values tested. The fall in sulphide produced can partly be accounted for by inhibition of sulphate reduction and partly by the chemical oxidation of sulphide by oxygen.

The main activity responsible for the increased respiration rate observed in the presence of oxygen seems to be NADH oxidase, which increased threefold in the experiments reported here. The increase in respiration would protect the cells by reducing oxygen to water or $\mathrm{H}_{2} \mathrm{O}_{2}$. It is likely that NADH oxidase is a flavoproteinlinked system in Desulfovibrio, rather than part of the terminal electron-transport chain involving cytochromes and other electron carriers used in aerobic respiration. Induction of NADH oxidase activity in the presence of oxygen has been reported in some anaerobic bacteria including Clostridium acetobutylicum (O'Brien \& Morrris, 1971), Cl. bifermentans (Ashley \& Shoesmith, 1977), Selenomonas ruminantium (Wimpenny \& Samah, 1978; Samah \& Wimpenny, 1982) and Peptostreptococcus anaerobius (Hoshino et al., 1978). On the other hand, Hardy \& Hamilton (1981) were unable to detect the activity in strains of Desulfovibrio vulgaris.

The presence of oxygen can give rise, either directly or through flavoprotein-mediated redox reactions, to active species such as the superoxide anion. Most organisms, including many obligate anaerobes, possess the enzyme superoxide dismutase which converts superoxide into oxygen and peroxide. Anaerobically grown $D$. desulfuricans had only low superoxide dismutase activity, but the activity rose more than tenfold in the presence of oxygen, suggesting that the enzyme represents an important defence mechanism in this organism. Superoxide dismutase has been shown to be present in a wide range of anaerobes including a Clostridium sp. (Hewitt \& Morris, 1975), Chromatium vinosum (Kanematsu \& Asada, 1978), Desulfovibrio desulfuricans (Hatchikian \& Henry, 1977), D. vulgaris (Hardy \& Hamilton, 1981) and Selenomonas ruminantium (Wimpenny \& Samah, 1978; Samah \& Wimpenny, 1982). In most cases where this has been examined, the activity of this enzyme increases with increases in environmental oxygen concentration. Possession of such protective mechanisms may help to explain the survival of sulphate-reducing bacteria in the presence of oxygen (Hardy \& Hamilton, 1981; Cypionka et al., 1985) and the relatively slow death rate of $D$. desulfuricans strain NCIB 8301 reported here.

\section{References}

ABDOLLAHI, H. (1979). Aspects of the ecology, physiology and serology of sulphate reducing bacteria. MPhil thesis, University of Essex, UK.

American Public Health Association (1971). Standard Methods for the Examination of Water and Waste Water, 13th edn. Washington, $\mathrm{DC}$.

Ashley, N. V. \& Shoesmith, J. G. (1977). Continuous culture of Clostridium sporogenes and Clostridium bifermentans in the presence of oxygen. Proceedings of the Society for General Microbiology 4, 144.

Cypionka, H., Widdel, F. \& PFennig, N. (1985). Survival of sulfate reducing bacteria after oxygen stress and growth in sulfate-free oxygen-sulfide gradients. FEMS Microbiology Ecology 31, 39-46.

DEPARTMENT OF THE ENVIRONMENT (1969). Analysis of Raw Potable and Waste Water. London: HMSO.

Hamilton, W. A. (1985). Sulphate reducing bacteria and anaerobic corrosion. Annual Review of Microbiology 39, 195-217.

HARDY, J. A. \& HAMilton, W. A. (1981). The oxygen tolerance of sulfate reducing bacteria isolated from North Sea waters. Current Microbiology 6, 259-262.

Hatchikian, E. C. \& HenRy, Y. A. (1977). An iron-containing superoxide dismutase from the strict anaerobe Desulfovibrio desulfuricans (Norway 4). Biochimie 59, 153-161.

HewitT, J. \& Morris, J. G. (1975). Superoxide dismutase in some obligately anaerobic bacteria. FEBS Letters 50, 315-318.

Hoshino, E., Frölander, F. \& Carlsson, J. (1978). Oxygen and the metabolism of Peptostreptococcus anaerobius VPI4330-1. Journal of General Microbiology 107, 235-248.

Hughes, D. E. (1951). A press for disrupting bacteria and other microorganisms. British Journal of Experimental Pathology 32, 97109.

JORGENSEN, B. B. (1982). Ecology of the bacteria of the sulphur cycle with special reference to anoxic-oxic interface environments. Philosophical Transactions of the Royal Society B298, 543-561.

Kanematsu, S. \& Asada, K. (1978). Superoxide dismutase from an anaerobic photosynthetic bacterium, Chromatium vinosum. Archives of Biochemistry and Biophysics 185, 473-482.

LloYd, D. \& BROOKMAN, J. S. G. (1967). An oxygen electrode reaction vessel. Biotechnology and Bioengineering 9, 271-272.

MCCORd, J. M. \& Fridovich, I. (1969). Superoxide dismutase: an enzymic function for erythrocuprein (hemocuprein). Journal of Biological Chemistry 244, 6049-6055.

MCCORD, J. M., KeELE, B. B., JR \& Fridovich, I. (1971). An enzymebased theory of obligate anaerobiosis: the physiological function of superoxide dismutase. Proceedings of the National Academy of Sciences of the United States of America 68, 1024-1027.

MoRrIs, J. G. (1975). The physiology of obligate anaerobiosis. Advances in Microbial Physiology 12, 169-246.

O'BriEN, R. W. \& MoRris, J. G. (1971). Oxygen and the growth and metabolism of Clostridium acetobutylicum. Journal of General Microbiology 68, 307-318. 
Postgate, J. R. (1984). The Sulphate Reducing Bacteria, 2nd edn. Cambridge: Cambridge University Press.

Pritchard, G. C., Wimpenny, J. W. T., Morris, H. A., Lewis,

M. W. A. \& Hughes, D. E. (1977). Effects of oxygen on Propionibacterium shermanii grown in continuous culture. Journal of General Microbiology 102, 223-233.

SAMAH, O. A. \& WIMPENNY, J. W. T. (1982). Some effects of oxygen on the physiology of Selenomonas ruminantium WPL 151/1 grown in continuous culture. Journal of General Microbiology 128, 355-360. SAPSHEAD, L. M. \& WimpenNy, J. W. T. (1972). The influence of oxygen and nitrate on the formation of the cytochrome pigments of the aerobic and anaerobic respiratory chain of Micrococcus denitrificans. Biochimica et Biophysica Acta 267, 388-397.

TsujI, K. \& YAGI, T. (1980). Significance of hydrogen burst from growing cultures of Desulfovibrio vulgaris Miyazaki, and the role of hydrogenase and cytochrome $c 3$ in energy production system. Archives of Microbiology 125, 34-42.

WiMPENNY, J. W. T. \& SaMaH, O. A. (1978). Some effects of oxygen on the growth and physiology of Selenomonas ruminantium. Journal of General Microbiology 108, 329-332. 